\title{
Ephrin-B/EphB Signaling Is Required for Normal Innervation of Lingual Gustatory Papillae
}

\author{
Randall William Treffy ${ }^{a}$ David Collins ${ }^{a} \quad$ Natalia Hoshino $^{a}$ Son Ton ${ }^{a}$ \\ Gennadiy Aleksandrovich Katsevman ${ }^{\text {a }}$ Michael Oleksiak $^{\mathrm{a}}$ \\ Elizabeth Marie Runge ${ }^{\mathrm{a}}$ David Cho ${ }^{\mathrm{a}}$ Matthew Russo ${ }^{\mathrm{a}}$ Andrej Spec $^{\mathrm{a}}$ \\ Jennifer Gomulka ${ }^{a}$ Mark Henkemeyer ${ }^{b}$ Michael William Rochlin ${ }^{a}$ \\ ${ }^{a}$ Department of Biology, Loyola University Chicago, Chicago, III., and bepartment of Developmental Biology, \\ UT Southwestern Medical Center, Dallas, Tex., USA
}

\section{Key Words}

Axon guidance $\cdot$ Neurotrophin $\cdot$ Epithelium - Taste .

Ephrin-B2 - Laminin

\begin{abstract}
The innervation of taste buds is an excellent model system for studying the guidance of axons during targeting because of their discrete nature and the high fidelity of innervation. The pregustatory epithelium of fungiform papillae is known to secrete diffusible axon guidance cues such as BDNF and Sema3A that attract and repel, respectively, geniculate ganglion axons during targeting, but diffusible factors alone are unlikely to explain how taste axon terminals are restricted to their territories within the taste bud. Nondiffusible cell surface proteins such as Ephs and ephrins can act as receptors and/or ligands for one another and are known to control axon terminal positioning in several parts of the nervous system, but they have not been studied in the gustatory system. We report that ephrin-B2 linked $\beta$-galactosidase staining and immunostaining was present along the dorsal epithelium of the mouse tongue as early as embryonic day 15.5 (E15.5), but was not detected at E14.5, when axons first enter
\end{abstract}

the epithelium. Ephrin-B1 immunolabeling was barely detected in the epithelium and found at a somewhat higher concentration in the mesenchyme subjacent to the epithelium. EphB1 and EphB2 were detected in lingual sensory afferents in vivo and geniculate neurites in vitro. Ephrin-B1 and ephrin-B2 were similarly effective in repelling or suppressing outgrowth by geniculate neurites in vitro. These in vitro effects were independent of the neurotrophin used to promote outgrowth, but were reduced by elevated levels of laminin. In vivo, mice null for EphB1 and EphB2 exhibited decreased gustatory innervation of fungiform papillae. These data provide evidence that ephrin-B forward signaling is necessary for normal gustatory innervation of the mammalian tongue.

(c) 2016 S. Karger AG, Basel

\section{Introduction}

The discrete nature of islands of gustatory epithelium embedded in a canvas of nongustatory epithelium makes the innervation of taste buds an excellent model system for investigating axon targeting mechanisms. Several

\section{KARGER}

E-Mail karger@karger.com

www.karger.com/dne
C 2016 S. Karger AG, Base

$0378-5866 / 16 / 0382-0124 \$ 39.50 / 0$
Michael William Rochlin, Assoc. Prof.

Biology Department, LSB 317B, Loyola University Chicago

1032 W. Sheridan Road

Chicago, IL 60660 (USA)

E-Mail wrochli@luc.edu 
groups have identified guidance cues that influence the timing of contact with and penetration of the pregustatory epithelium during embryonic development. Diffusible repellents are implicated in controlling the timing of contact with the epithelium $[1,2]$, and diffusible neurotrophins have a prominent role in the final stage of guidance to gustatory papillae and target penetration [3-15]. Given that taste axons are ultimately restricted to taste bud epithelium, yet can reside adjacent to nontaste epithelium, we reasoned that nondiffusible guidance cues may have a role in preventing innervation of nontaste epithelium or otherwise restricting the arbors of taste axons. Extracellular matrix proteins, including laminin and tenascin, are nondiffusible guidance cues for peripheral axons that are known to be present in the core of gustatory papillae [16-19] and presumably support the growth of axons or restrict incoming axons to appropriate regions. Since there is little extracellular matrix within papilla epithelium, cell-cell interactions are likely to have a more prominent role than cell-extracellular matrix interactions in controlling the final position of taste axons, motivating us to explore the involvement of Eph/ephrin signaling in taste axon targeting.

Ephs and ephrins are cell-attached proteins that can act as receptors and/or ligands for one another to initiate signaling cascades resulting in repulsion, stabilization, growth promotion or branching of axons [20-23]. Although most studies have focused on their role in the guidance of axons in the central nervous system, they are also implicated in the guidance of axons in the peripheral nervous system during development and regeneration. Eph/ephrin signaling influences the rostrocaudal targeting of motor axons [24, 25]. Appropriate targeting of sensory neurons of dorsal root ganglia $[26,27]$, the trigeminal ganglion [28], the vestibular ganglion [29], and the cochlear ganglion [30] depends on Eph/ephrin signaling as well. The role of Eph/ephrin signaling in the innervation of taste buds and surrounding epithelium has not been explored.

There are two classes of Ephs and ephrins. Ephrin-Bs are transmembrane proteins that interact primarily with EphBs, whereas ephrin-As are glycosylphosphatidylinositol-linked proteins that interact primarily with EphAs [21]. The Ephs constitute one of the largest families of receptor tyrosine kinases and mediate 'forward signaling' triggered by the interaction with ephrins on adjacent cell membranes. The ephrins are also capable of initiating signaling cascades in their cells when activated by Ephs from adjacent cells, termed 'reverse signaling' [20]. Owing to preliminary studies indicating that ephrin-Bs were pres- ent in lingual tissue at targeting stages, our initial study focused on the roles of ephrin-Bs and EphBs in taste axon targeting. We report that ephrin-B2 is expressed in the lingual epithelium during penetration by taste afferents and that EphBs are expressed in gustatory afferents arising from the geniculate ganglion, and we provide evidence that EphB signaling is sufficient to repel geniculate neurites in vitro and necessary for normal innervation in vivo. We also studied the influence of neurotrophin signaling and laminin concentration on the response of taste axons to ephrin-Bs in vitro.

\section{Methods}

All procedures are IACUC approved. The morning that dams are determined to be sperm positive is defined as embryonic day 0.5 (E0.5) for mice or E1 for rats.

\section{Immunofluorescence on Wild-Type Rat and Mouse}

Cryosections

After the embryos were removed from the dams, the tongues were dissected, immersion fixed in $4 \%$ paraformaldehyde in phosphate-buffered saline (PBS) and cryosectioned $(20 \mu \mathrm{m})$. Sections were briefly rehydrated in PBS. If tyramide/Cy3 amplification was planned, then rehydrated sections were dehydrated with a methanol series, and endogenous peroxidases were quenched with Dent's fixative [31] for ephrin-B2 labeling or 3\% peroxide in PBS for ephrin-B1 labeling. After blocking and permeabilizing with PBSTD (PBS with 1\% tween-20, 5\% DMSO) containing $1 \%$ fish gelatin and $1.4 \mathrm{mg} / \mathrm{ml} \mathrm{BSA}$ (all reagents from Sigma), sections were labeled overnight with primary antibodies: $2 \mathrm{H} 3$ mouse anti-neurofilament protein, mouse anti-EphB1-3 and hamster monoclonal antiephrin-B1 (DSHB); goat anti-EphB1, goat anti-EphB2, goat antiEphB3, goat anti-ephrin-B1 and goat anti-ephrin-B2 (Biotechne); rabbit anti-PGP9.5 (Biogenesis), mouse anti-GAP43 (Millipore) and rabbit anti-P2X3 (Millipore). For routine immunofluorescence, Alexa Fluor-conjugated secondary antibodies (Life Technologies) were used to detect primary antibodies. For tyramide amplification, we used a secondary antibody conjugated to horseradish peroxidase (Jackson ImmunoResearch) and kits obtained from Life Technologies or Perkin-Elmer. The slides were then mounted in Vectashield (Vector Laboratories) and imaged on an Olympus FluoView 1000 confocal microscope. Z-stack projections were used for all images.

Detection of Ephrin-B2 Expression in Transgenic Mice

Ephrin-B2 $2^{\text {lacZ }}$ mice were created by replacing the cytosolic domain of ephrin-B2 with lacZ [32, 33]. X-gal staining was carried out as previously described [33].

\section{Tissue Culture}

Coverglasses with stripes of ephrin-B-Fc recombinant proteins were prepared as described by Knoll et al. [34]. Briefly, 22-mm glass coverslips were first coated with poly-D-lysine or poly-L-lysine $\left(0.1 \mathrm{mg} / \mathrm{ml}\right.$, incubated for $2 \mathrm{~h}$ at $37^{\circ} \mathrm{C}$, no differences were noted), rinsed twice with deionized water, sterilized with $70 \%$ eth- 
anol, and air-dried under sterile conditions. Solutions for the first and second stripes were then prepared as described below. For experimental coverglasses, first stripe solutions contained ephrinB-human-Fc fusion proteins (Biotechne); for control coverglasses, first stripe solutions contained human IgG Fc (Millipore). The fusion proteins or IgG Fc were preclustered for $30 \mathrm{~min}$ on ice with $5 \mu \mathrm{g} / \mathrm{ml}$ Alexa Fluor 488 goat anti-human antibody (Molecular Probes) in Hanks' balanced salt solution (HBSS, Life Technologies). First stripes were prepared using $2-40 \mu \mathrm{g} / \mathrm{ml}$ ephrin-B-Fc fusion protein or $40 \mu \mathrm{g} / \mathrm{ml}$ human IgG Fc, as indicated in the text. For the second stripe solution, human IgG Fc (the same concentration as ephrin-B-Fc) was preclustered as above but with $5 \mu \mathrm{g} / \mathrm{ml}$ unconjugated goat anti-human Fc (Millipore) in HBSS. Next, silicone manifolds with $90-\mu \mathrm{m}$ channels were applied to polylysinetreated coverglasses; $100 \mu \mathrm{l}$ of the first stripe solution was then deposited into the matrices and incubated at $37^{\circ} \mathrm{C}$ for $30 \mathrm{~min}$. After 3 washes with HBSS to remove unbound protein, the matrices were removed, and $100 \mu \mathrm{l}$ of the second stripe solution was deposited and incubated again at $37^{\circ} \mathrm{C}$ for $30 \mathrm{~min}$, allowing it to coat the unbound region between the first stripes. Following 3 more washes in HBSS, the coverslips were incubated for $2 \mathrm{~h}$ at $37^{\circ} \mathrm{C}$ (or overnight at $4^{\circ} \mathrm{C}$ ) in $100 \mu \mathrm{l}$ of solution containing $2.5 \mu \mathrm{g} / \mathrm{ml}$ or $20 \mu \mathrm{g} /$ $\mathrm{ml}$ laminin (BD Biosciences) in HBSS, followed again by 3 HBSS washes (see Results). To prepare coverglasses with a uniform coating of ephrin $(0.5-10 \mu \mathrm{g} / \mathrm{ml})$, a similar procedure was followed, but without the use of matrices. Initially, uniform control coverglasses were prepared with human IgG Fc at $10-40 \mu \mathrm{g} / \mathrm{ml}$, but we determined that this had no effect on outgrowth and omitted the IgG Fc from the uniform control coverglasses. Ganglia explants were dissected under sterile conditions, plated on the coverslips in 100 $\mu \mathrm{l}$ serum-free medium containing Neurobasal Medium (Life Technologies), $1.4 \mathrm{mM}$ L-glutamine (Life Technologies), N2 supplement (Life Technologies) and $10 \mathrm{ng} / \mathrm{ml} \mathrm{BDNF}$ (Prospec), or $1 \mathrm{ng} /$ $\mathrm{ml} \mathrm{NT} 4$ (Sigma) and cultured for $25-30 \mathrm{~h}$ at $35^{\circ} \mathrm{C}$ with $5 \% \mathrm{CO}_{2}$.

For labeling, cultures were treated with $4 \%$ paraformaldehyde (at $37^{\circ} \mathrm{C}$ ) in $0.1 \mathrm{M}$ cacodylate $\left(\mathrm{pH} 7.4\right.$ ) containing $10 \mathrm{mM} \mathrm{MgCl}_{2}$ and $5 \mathrm{mM} \mathrm{CaCl}_{2}$ for $12 \mathrm{~min}$ [35]. Cultures were washed with $0.1 \mathrm{M}$ cacodylate buffer followed by PBS, treated with PBSTD block, followed by a 1-hour incubation in anti-neurofilament $(2 \mathrm{H} 3,1: 80$; Developmental Studies Hybridoma Bank) and mouse anti-GAP43 (1:2,000, Millipore). Cultures were then washed 3 times in PBSTD, and incubated for $40 \mathrm{~min}$ in donkey anti-mouse Alexa 555 (1:600, Life Technologies). Following 3 more washes in PBSTD, cultures were mounted in Vectashield.

For measurements of ephrin stripe images, stripes were oriented vertically, and ganglion outgrowth was divided into quadrants. We measured the longest neurite outgrowth that was continuous in the labeled stripes within the upper and lower quadrants (i.e. approx. parallel to the stripes) for each ganglion, and took the ratio of that value to the length of the longest neurites in the unlabeled stripe for the same ganglion. Neurites that crossed over into different stripes were disregarded. For uniformly coated coverglasses, two measurements of the furthest extent of the halo of outgrowth were taken from the same quadrant for each ganglion and averaged. We did not include data from coverglasses that were coated with a batch of laminin that was found to be less effective than a subsequently used batch. Outgrowth on these coverglasses was notably shorter than on those prepared using more recently purchased laminin. We omitted data from 2 coverglasses in which there appeared to be anomalously low outgrowth (every ganglion explant exhibited $55 \%$ or less of the average outgrowth of ganglia from the other coverglasses used for that condition). We also excluded the data from 1 experiment in which 9 of the 10 conditions ( 27 out of 30 ganglia) had notably lower neurite outgrowth than when the same conditions were used in other experiments. For both uniform and stripe measurements, statistical outliers were excluded as well. At least 3 experiments were performed for each condition.

\section{Innervation in Mouse Mutants Lacking Ephs}

EphB1 $1^{-/} / E p h B 2^{-/-}$embryos were obtained by mating $E p h B 1^{-/-} / E p h B 2^{-/-}$males with EphB1 $1^{-/-} / E p h B 2^{-/+}$females. The $E p h B 1^{-/-}$mice [36] and EphB2 $2^{-/-}$mice [37] were generated as described previously. EphB1 $1^{-/-} / E p h B 2^{-/-}$embryos were generated at E13.5, E15.5 and E17.5. The E13.5 embryo heads were fixed by immersion in $4 \%$ paraformaldehyde, and the older embryos were fixed by perfusion with cold $4 \%$ paraformaldehyde in PBS followed by postfixation overnight in $4 \%$ paraformaldehyde at $4{ }^{\circ} \mathrm{C}$. DiI labeling from the geniculate ganglion was carried out as described previously [6]. The tongues were cleared in $80 \%$ glycerol, and the dorsal surfaces were imaged on an Olympus FluoView 1000 confocal microscope. We then prepared parasagittal vibratome sections of the tongues ( $75 \mu \mathrm{m}$ for E13.5 tongues, $100 \mu \mathrm{m}$ for E15.5 and E17.5 tongues), imaged these on the confocal microscope and analyzed the images as described in Results.

\section{Results}

\section{Ephrin-B and EphB Expression in the Taste System during Lingual Innervation}

Previous investigations have established the progress of gustatory innervation during embryonic mouse and rat development. At E12.5 in mice ( $\sim$ E15 in rats) the chorda tympani has branched within the tongue mesenchyme and begun to exhibit targeting toward nascent fungiform papillae. At E13.5 ( E16 in rats), fascicles of taste axons are nearly touching the fungiform papilla epithelium, and the first axons penetrate this epithelium on E14.5 ( E17 in rats). By E15.5 ( E18 in rats), many axons have entered the epithelium in the center of the papilla where the taste bud has begun to develop. At E16.5, the proportion of innervated fungiform papillae has reached its maximum [38]. For immunolocalization, we obtained two well-characterized antibodies against ephrin-B1, a hamster monoclonal [39] and a goat polyclonal. Both antibodies strongly labeled the mesenchyme surrounding the spinal cord and dorsal root ganglia in spinal cord cross sections, as expected [40], and we could detect dorsal radial glia that are known to express ephrin-B1 (fig. 1a) [41]. In the E12.5-17.5 mouse tongue, anti-ephrin-B1 labeling was barely detectable in the lingual epithelium and was uniformly distributed (fig. $1 \mathrm{a}^{\prime}, \mathrm{a}^{\prime \prime}$ ). The strongest anti-ephrin-B1 labeling in the tongue at these stages was in 

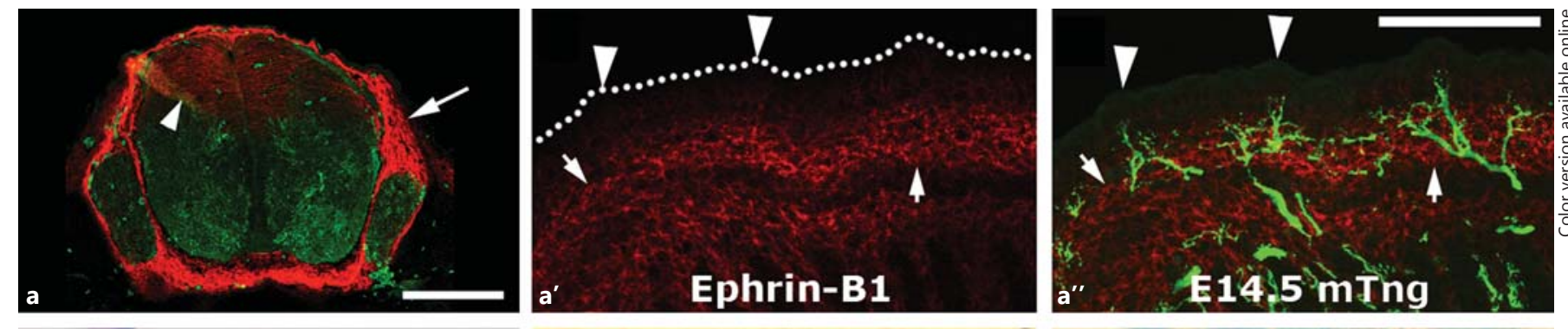

b Ephrin-32 lacz, $=15.5$

c Ephrin-B2 lacZ, E16.5
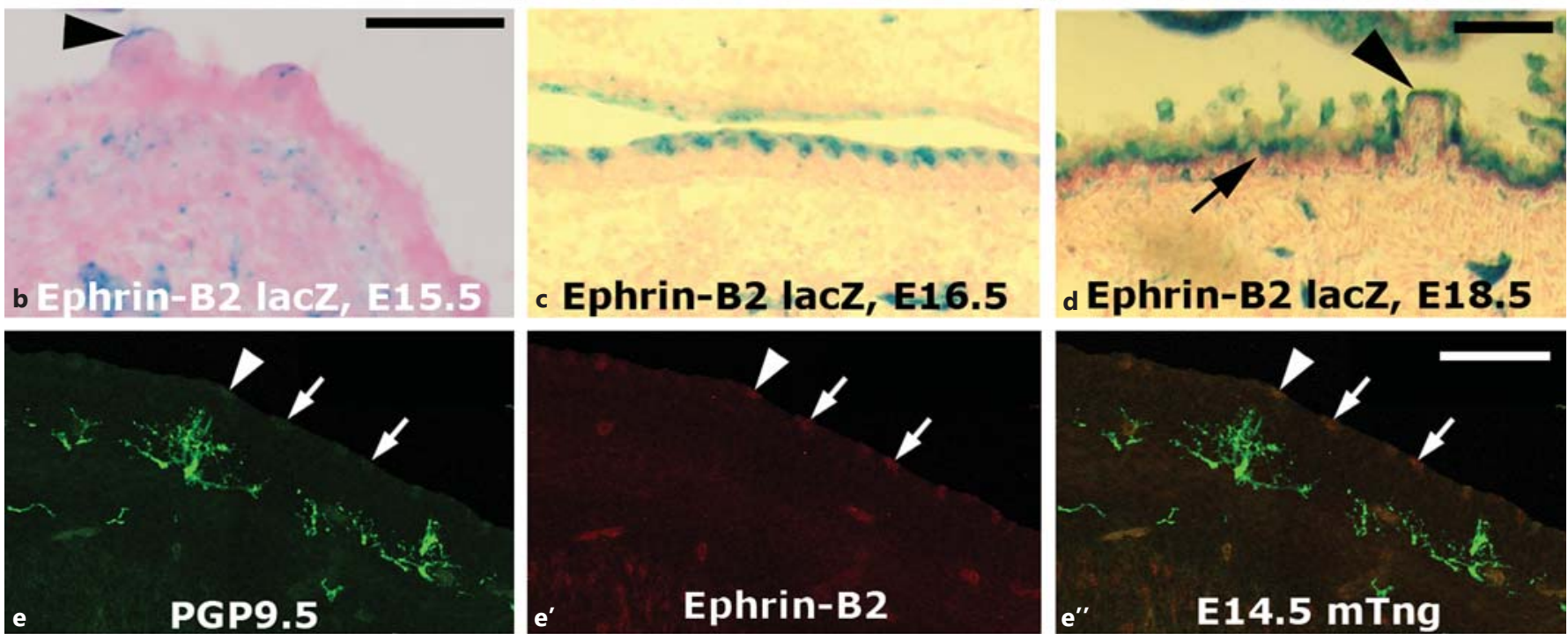

d Ephrin-B2 lacZ, E18,5
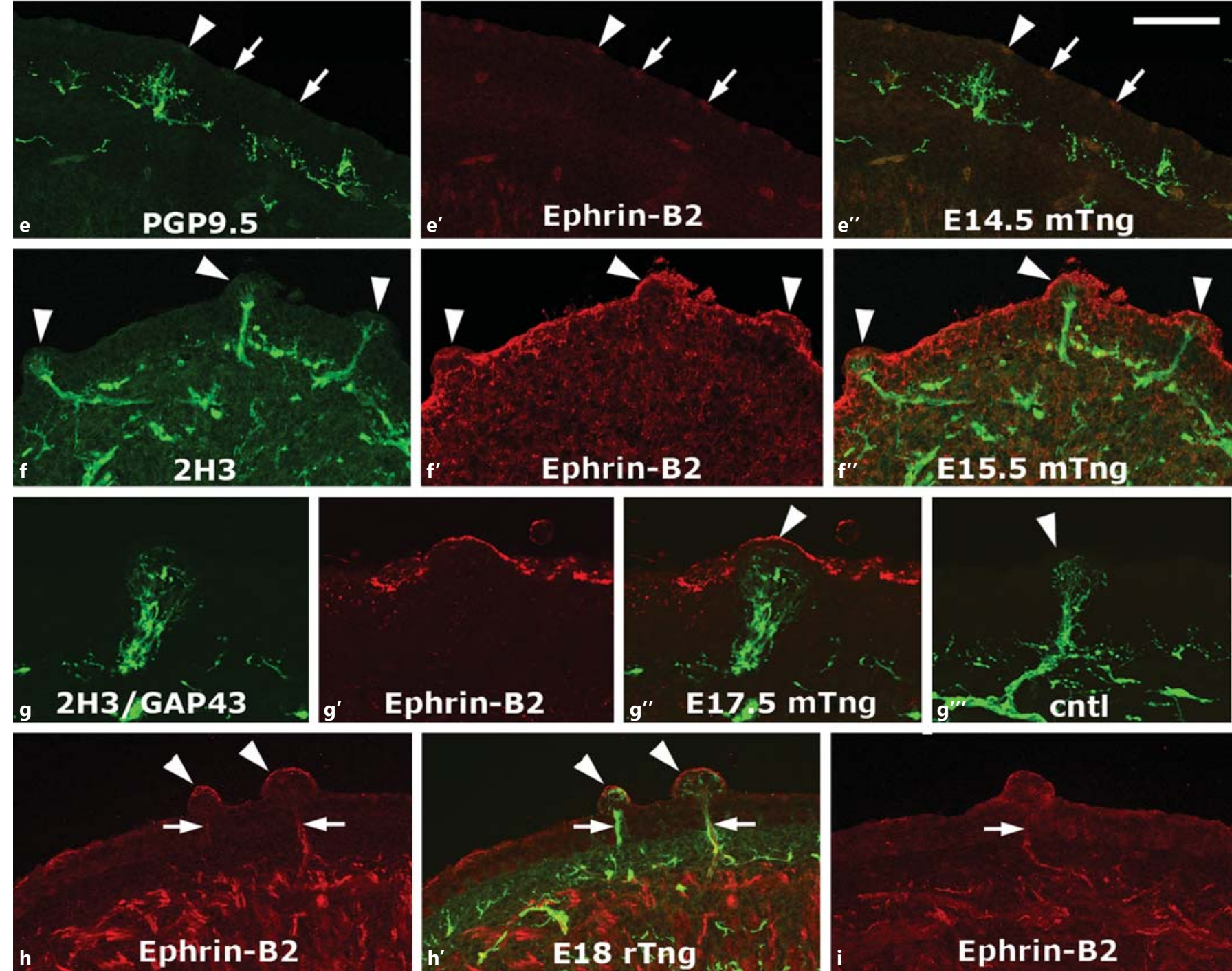

E15.5 mTng
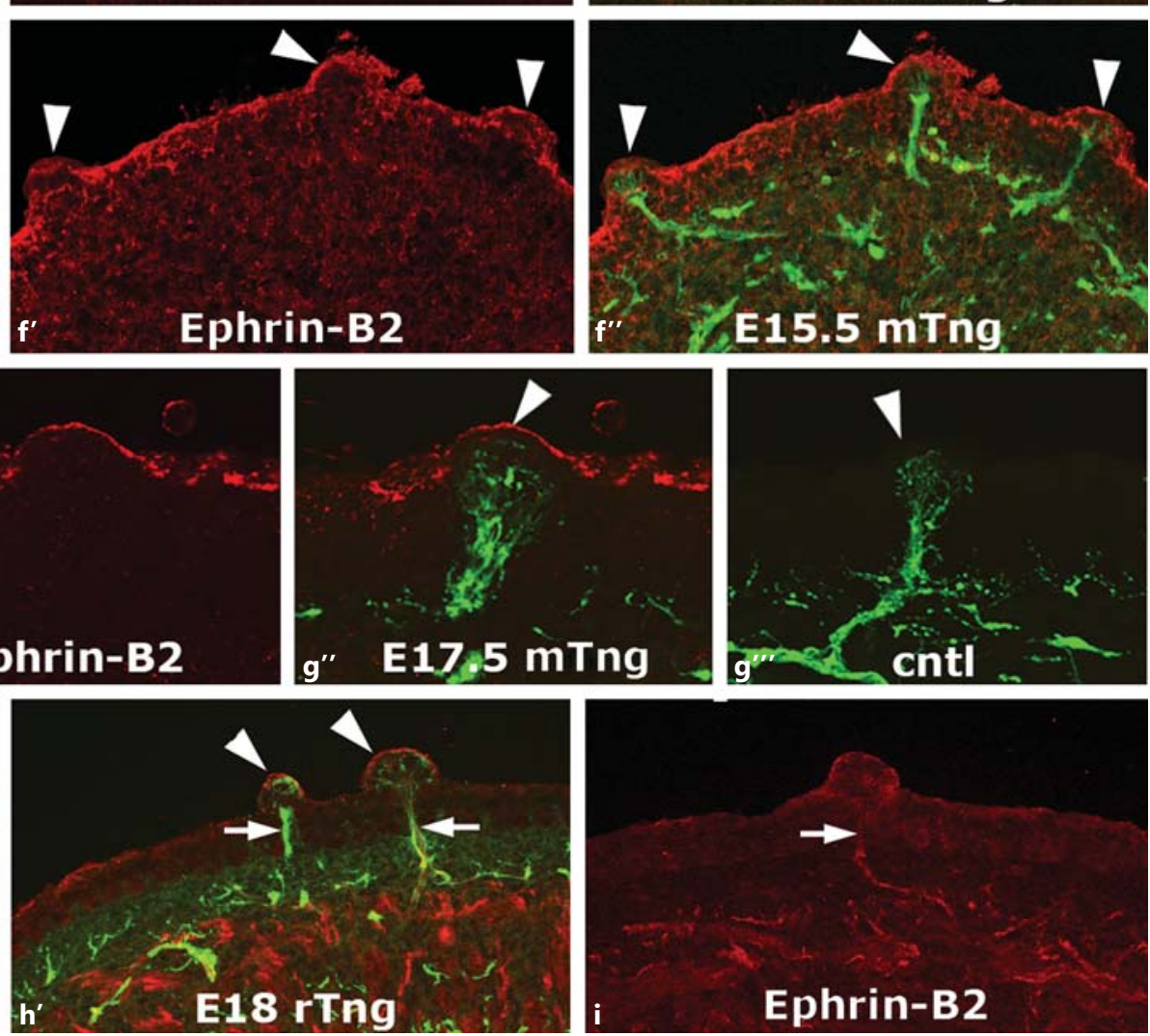

(For legend see next page.) 
a band of mesenchyme beneath the epithelium (fig. 1a', arrows). We obtained similar immunostaining results with E15 and E18 rat embryos. These data do not support a role for ephrin-B1 in the guidance of sensory axons at the lingual epithelium.

For ephrin-B2 localization, we used ephrin-B2 lac mice, in which $\beta$-galactosidase replaced the cytosolic domain of ephrin-B2 [32, 33], and immunostaining. Ephrin-B2-lacZ is known to be expressed on the plasma membranes of cells that normally express ephrin-B2 [33]. No labeling was found in the E14.5 mouse tongue, but beginning at E15.5 a low level of lacZ staining was evident in some fungiform papillae near the tip of the tongue (fig. 1b) and also at more posterior fungiform papillae. In addition, we observed intense, intermittent staining along the serosal surface of the dorsal epithelium in the posterior half of the tongue at E15.5 and along the posterior three quarters of the tongue at E16.5 (fig. 1c). This staining showed no relationship to fungiform papillae. By E18.5, ephrin-B2 lacZ staining was continuous along the dorsal surface of the tongue, but in fungiform papillae it appeared restricted to the apical-most surface of the epithelium (fig. 1d).

Immunolabeling gave results similar to those obtained in the ephrin-B2 $2^{\text {lacZ }}$ mice (fig. $1 \mathrm{f}-\mathrm{g}^{\prime \prime \prime}$ ), though epithelial staining in the mouse was detectable at E14.5 (fig. 1e-e $\mathrm{e}^{\prime \prime}$ ) and appeared more continuous along the dorsal epithe-

Fig. 1. Localization of ephrin-B1 and ephrin-B2 in and near the dorsal lingual epithelium during target penetration by sensory afferents. $\mathrm{mTng}=$ Mouse tongue; $\mathrm{rTng}=$ rat tongue $\mathrm{cntl}=$ control. a-a" TSA Plus-enhanced monoclonal ephrin-B1 immunostaining. a We labeled sections of mouse E12.5 spinal cord as a positive control for ephrin-B1 immunostaining. Anti-ephrin-B1 (red; color in online version only) strongly labels the mesenchyme surrounding the spinal cord and dorsal root ganglia (arrow), and moderately labels dorsal radial glia (arrowhead). PGP9.5 staining is shown in green. $\mathbf{a}^{\prime}, \mathbf{a}^{\prime \prime}$ Ephrin-B1 staining (red) was found in the tissue subjacent to the epithelium ( $\mathbf{a}^{\prime}$, arrows) and is difficult to detect in the epithelium, including the fungiform papillae (arrowheads). The oral surface of the epithelium is marked by dots. PGP9.5 was used to label axons (green). Note that the brightness and contrast of the ephrin-B1 staining has been enhanced; it is dimmer than the positive control staining of the dorsal radial glia in the spinal cord (a, arrowhead). b-d LacZ staining in ephrin$B 2^{\text {lac } Z}$ mouse embryos. A low level of ephrin-B2 lacZ staining was often detected at the serosal surface of fungiform papilla epithelium at E15.5 (b, arrowhead) and E16.5. In addition, more intense periodic lacZ staining was found in the posterior half (E15.5) and three quarters $(\mathrm{E} 16.5, \mathrm{c})$ of the apical aspect of the dorsal lingual epithelium. By E18.5 (d), the ephrin-B2 lacZ staining was continuous along the dorsal epithelium of the tongue (arrow), but more lium at E15.5 and E16.5 (fig. $1 \mathrm{f}-\mathrm{f}^{\prime \prime}, 2 \mathrm{~g}^{\prime}$ ). This difference in immunostaining versus the staining in ephrin-B2 $2^{\text {lac } Z}$ mice is most likely attributable to the difficulty of blocking all nonspecific labeling of epithelia. Immunolabeling carried out in rat tongue sections gave similar results for the epithelium (fig. $1 \mathrm{~h}, \mathrm{~h}^{\prime}, \mathrm{i}$ ), but surprisingly, not for sensory nerves; in parasagittal sections of mouse tongue, ephrin-B2 immunolabeling of sensory afferents was not detectable at E13.5, 14.5, 15.5 and 16.5. In the E17 and E18 rat, anti-ephrin-B2 labeled lingual sensory nerves within the tongue musculature and the core of fungiform papillae (fig. $1 \mathrm{~h}, \mathrm{~h}^{\prime}, \mathrm{i}$ ). The staining intensity was variable in rat nerves, and was typically thinner than neurofilament/ GAP43 staining, primarily overlapping with only the most intense neurofilament/GAP43 staining. To determine whether this staining was due to the detection of neurofilament/GAP43 staining in the ephrin-B2 channel, we stained sections with anti-ephrin-B2 only and observed identical staining (fig. 1i). We also labeled neurites in explant cultures and found that geniculate neurites exhibited a low level of ephrin-B2 staining, whereas nonneuronal cells were negative (fig. 2e), suggesting that the in vivo nerve staining was from axons rather than glial cells.

We used immunohistochemistry to detect EphB1, EphB2, EphB3 and EphB4 in tongue sections and in vitro. Anti-EphB1 weakly labeled sensory nerves in E18 rat

apically restricted within fungiform papillae (arrowhead). e-e" Intermittent anti-ephrin-B2 labeling (red, arrows) was evident along the oral surface of the lingual epithelium, including fungiform papilla epithelium (arrowheads) as early as E14.5 in the mouse. f$\mathbf{f}^{\prime \prime}$ In E15.5 mouse tongue (f'), anti-ephrin-B2 staining ( $\left.\mathbf{f}^{\prime}\right)$ was typically continuous along the dorsal lingual epithelium, including fungiform papilla epithelium (arrowheads, $\mathbf{f}-\mathbf{f}^{\prime \prime}$ ), and did not colocalize with $2 \mathrm{H} 3$ anti-neurofilament nerve staining (f). g-g'"' Anti-ephrin-B2 labels the serosal surface of a murine E17.5 fungiform papilla ( $\mathbf{g}^{\prime}$, arrowhead in $\left.\mathbf{g}^{\prime \prime}\right)$ that is substantially innervated $(\mathbf{g})$. A combination of 2 monoclonal antibodies, $2 \mathrm{H} 3$ and anti-GAP43, was used to detect axons. In the negative control in which no primary antibody was applied ( $\left.\mathbf{g}^{\prime \prime \prime}\right)$, no staining was observed in the red channel in fungiform papilla (arrowhead). h-i In the E18 rat tongue, however, ephrin-B2 labeling (red) was present in fungiform papilla epithelium (arrowheads, $\mathbf{h}, \mathbf{h}^{\prime}$ ) but also colocalized with 2H3/GAP43-labeled afferents ( $\mathbf{h}^{\prime}$, green). This staining was also observed when anti-ephrin-B2 was the only antibody used to label the tongue section (i), showing that it is not due to 'bleed through' or adventitious excitation of the Alexa Fluor 488 that we typically use to detect $2 \mathrm{H} 3 / \mathrm{GAP} 43$ in the axons. Calibration bar in $\mathbf{a}=250 \mu \mathrm{m}$; bar in $\mathbf{a}^{\prime \prime}=100 \mu \mathrm{m}$; bars in $\mathbf{b}, \mathbf{d}$ and $\mathbf{e}^{\prime \prime}=50 \mu \mathrm{m}$. Bar in $\mathbf{b}$ applies to $\mathbf{c}$ and bar in $\mathbf{e}^{\prime \prime}$ applies to $\mathbf{e}-\mathbf{i}$. 

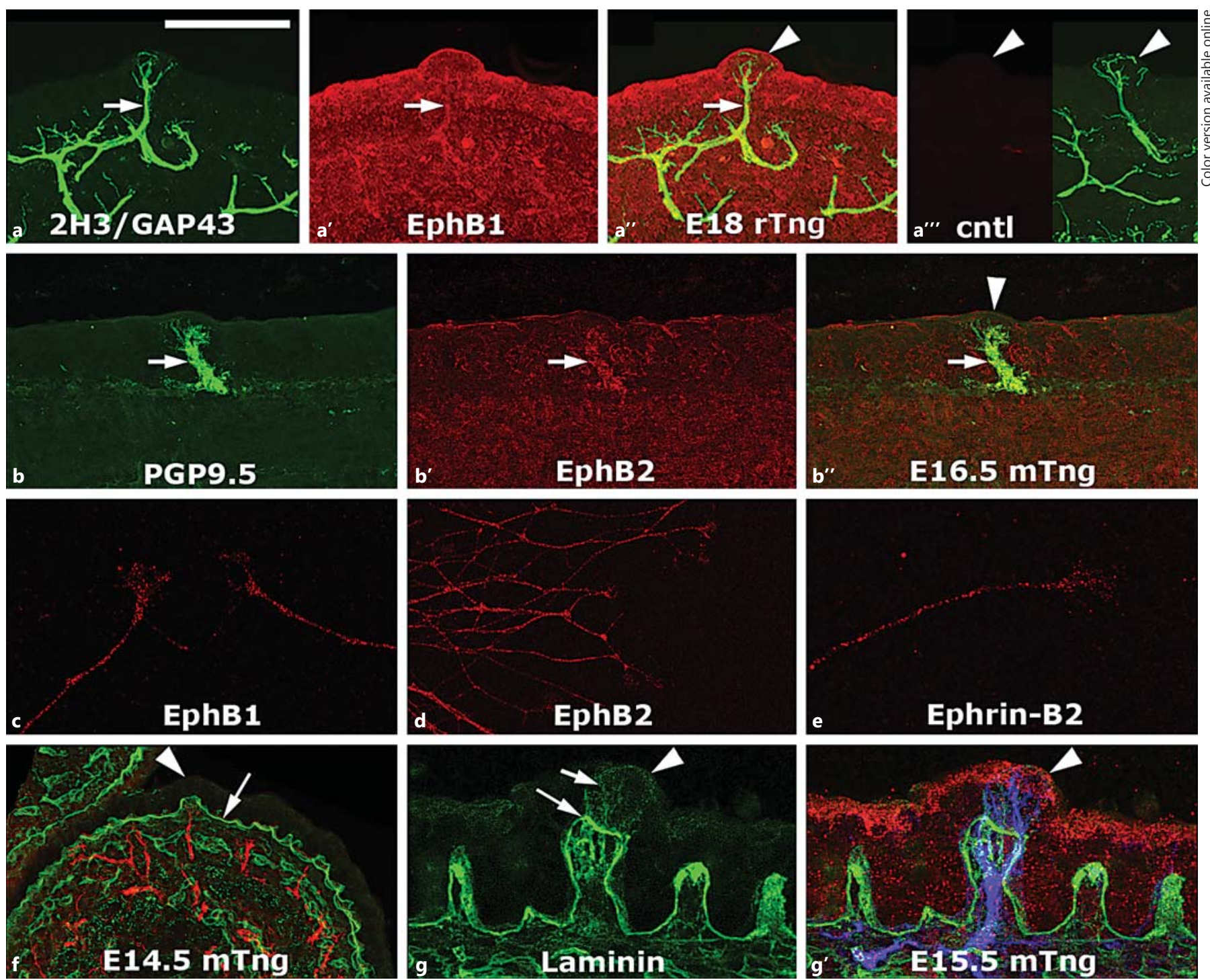

Fig. 2. Localization of EphBs, ephrin-B2, and laminin during innervation of the lingual epithelium. $\mathrm{mTng}=$ Mouse tongue; rTng = rat tongue; cntl = control. a-a'"' Anti-EphB1 (a') and 2H3/ GAP43 (a) detect sensory afferents near and within the fungiform papilla epithelium in an E18 rat tongue (a", arrowhead). In $\mathbf{a}^{\prime \prime \prime}$, the right panel shows 2H3/GAP43 labeling in an E18 fungiform papilla (arrowhead) and the left side shows the negative control for EphB1 labeling in which no primary antibody was applied and in which no signal was detected. b-b" A low level of EphB2 immunoreactivity $\left(\mathbf{b}^{\prime}\right)$ was also detected in lingual afferents labeled with anti-PGP9.5 (b), arrows. An overlay of $\mathbf{b}$ and $\mathbf{b}^{\prime}$ is provided in $\mathbf{b}^{\prime \prime}$, in which the arrowhead designates a fungiform papilla. c-e In vitro labeling of E18 rat geniculate ganglion neurites. Anti-EphB1 (c) and anti-EphB2 (d) labeling is evident in geniculate neurites. Anti-
ephrin-B2 (e) also weakly labels rat geniculate neurites. $\mathbf{f}-\mathbf{g}^{\prime}$ Antilaminin (f, green; color in online version only) labels the basal lamina beneath the epithelium (f, arrow) and the lamina propria at E14.5 in the mouse, when afferents (red) are just beginning to enter the fungiform papilla epithelium (arrowhead). The distribution of laminin (green) is similar at E15.5 (g), after penetration of the papilla epithelium by sensory afferents. Note that laminin staining within the papilla epithelium (short arrow) is dimmer than the staining in the connective tissue core of the papilla (long arrow). In $\mathbf{g}^{\prime}$, afferents (blue, 2H3/GAP43 staining) and ephrin-B2 immunoreactivity in the epithelium are also shown (red). Calibration bar in $\mathbf{a}=50 \mu \mathrm{m}$ and applies to $\mathbf{a}-\mathbf{f}$ except for $\mathbf{c}$ and $\mathbf{e}$, which are rendered at 3-fold high magnification, as are $\mathbf{g}$ and $\mathbf{g}^{\prime}$. 
tongues (fig. 2a-a $\mathrm{a}^{\prime \prime \prime}$ ) and geniculate neurites in vitro (fig. 2c). EphB2 labeling was similar to EphB1 labeling, but weaker (fig. $2 b-b^{\prime \prime}, d$ ). We did not observe nerve staining with anti-EphB3 or anti-EphB4 in mouse and rat tongue sections (data not shown). We note that we also tested a mouse monoclonal antibody obtained from the Developmental Studies Hybridoma Bank that recognizes EphB1, B2 and B3 [39], but we discovered that this antibody detects microtubules to a much greater extent than any cell surface protein, at least in vitro. The localization of ephrin-B2 and EphB1/EphB2 supports a role for forward ephrin- $\mathrm{B} / \mathrm{EphB}$ signaling during axon targeting within the lingual epithelium.

\section{Dose-Dependent Effects of Ephrin-B1-Fc and Ephrin-}

$B 2-F c$ in vitro

Since ephrin-B1 labeling was detectable in the mesenchyme and ephrin-B2 was present in the lingual epithelium, we conducted stripe assays to determine whether ephrin-B1-Fc or ephrin-B2-Fc fusion proteins repelled or stabilized geniculate neurite outgrowth in vitro. To promote outgrowth, we used BDNF and NT4 because both are required for geniculate neuron survival [42] and promote substantial geniculate neurite outgrowth in vitro $[11,12]$. Neither NGF nor NT3 support outgrowth from geniculate explants [1]. We focused on BDNF because it has a more prominent role than NT4 at targeting stages; $\mathrm{BDNF}$ is upregulated in fungiform epithelium just prior to innervation [15] and is necessary for targeting [10, 43, 44], while NT4 is downregulated in the epithelium prior to innervation [4] and is not necessary for the guidance of taste afferents [44]. Experimental coverglasses were coated with alternating stripes of labeled ephrin-B1-Fc or ephrin-B2-Fc fusion protein and unlabeled stripes of human IgG Fc (see Methods). Since results obtained with ephrin-B1-Fc and ephrin-B2-Fc were essentially the same, we provide examples only from ephrin-B1-Fc experiments (fig. 3). Control coverglasses were coated with alternating stripes of labeled and unlabeled human IgG Fc. Neurites from rat geniculate ganglia obtained at E15 or E18 showed no preference for either stripe on control coverglasses (fig. 3a, 4a, b, white bars adjacent to green and blue bars). On experimental coverglasses, neurites emitted parallel to ephrin-Fc stripes grew significantly less on the ephrin-B1 or ephrin-B2 stripes than control stripes if 10 or $40 \mu \mathrm{g} / \mathrm{ml}$ ephrin-B-Fc, but not $2 \mu \mathrm{g} / \mathrm{ml}$ ephrin-B-Fc, was used to prepare the test stripe (fig. $3 \mathrm{a}-\mathrm{d}$, $4 a, b)$, indicating that high concentrations of either ephrin- $\mathrm{B}$ repel geniculate axons. The repulsion produced by $10 \mu \mathrm{g} / \mathrm{ml}$ ephrin-B-Fc was significantly less than that ob- served with $40 \mu \mathrm{g} / \mathrm{ml}$ stripes of either ephrin, showing that ephrin-B repulsion is dose dependent.

Although NT4 is not required for targeting, it is more potent than BDNF in promoting neurite outgrowth [11], so we also evaluated the response of NT4-promoted neurite outgrowth to ephrin-B-Fc stripes. We note that NT4, like BDNF, is necessary for the survival of half of the geniculate neurons, and mice null for both BDNF and NT4, or their high affinity receptor TrkB, lose $95 \%$ of the geniculate neurons $[45,46]$. Although this is consistent with the possibility that BDNF and NT4 support distinct populations of neurons, the finding that NT4 can substitute for BDNF [3] suggests that BDNF and NT4 support the same population of geniculate neurons. NT4-promoted outgrowth showed no preference for either stripe on control coverglasses (fig. 4a, b, white bars adjacent to purple bars) or on coverglasses prepared with $2 \mu \mathrm{g} / \mathrm{ml}$ ephrin-B2-Fc stripes at E18 (fig. 4b, lightest purple bar). We found that NT4-promoted neurite outgrowth from E15 and $\mathrm{E} 18$ geniculate ganglia was repelled by $40 \mu \mathrm{g} / \mathrm{ml}$ ephrin-B2 stripes, and that E18 neurites were repelled by 10 $\mu \mathrm{g} / \mathrm{ml}$ ephrin-B2 stripes as well (fig. $4 \mathrm{a}$, b, darker purple bars).

Neurites emitted from ganglion explants perpendicular to the stripes often crossed even the $40 \mu \mathrm{g} / \mathrm{ml}$ ephrin-B stripes, suggesting that repulsion is not always the dominant influence on the direction taken by the growth cones. Notably, the outgrowth halo perpendicular to the stripes was significantly shorter than that parallel to the stripes (data not shown). This could be due in part to neurites turning to avoid growing on the second or third ephrin stripe that they encountered, and may also be due to the inhibition of outgrowth while crossing ephrin stripes. We assessed the latter possibility as discussed below.

To determine whether ephrin-B1 or ephrin-B2 is sufficient to promote (at low concentrations [47]) or suppress geniculate outgrowth, we plated explants on coverglasses that were uniformly coated with ephrin-B-Fc fusion proteins. A dose-response assay was carried out, using concentrations of $0.5,2$ and $10 \mu \mathrm{g} / \mathrm{ml}$ ephrin-B1-Fc or ephrin-B2-Fc. At E15, neither ephrin-B1-Fc nor ephrin-B2-Fc stimulated BDNF-supported outgrowth at any concentration, but $10 \mu \mathrm{g} / \mathrm{ml}$ of either ephrin-B-Fc suppressed BDNF-supported outgrowth compared to control outgrowth (fig. $4 \mathrm{~d}$, green and blue bars). NT4-stimulated outgrowth was suppressed at both 2 and $10 \mu \mathrm{g} / \mathrm{ml}$ ephrin-B2 (fig. 4d, purple bars). At E18 all three concentrations of ephrin-B1 suppressed outgrowth significantly (fig. 4e, green bars), but only the highest concentration of ephrin-B2 suppressed BDNF-stimulated (fig. 3e-h, 4e, 


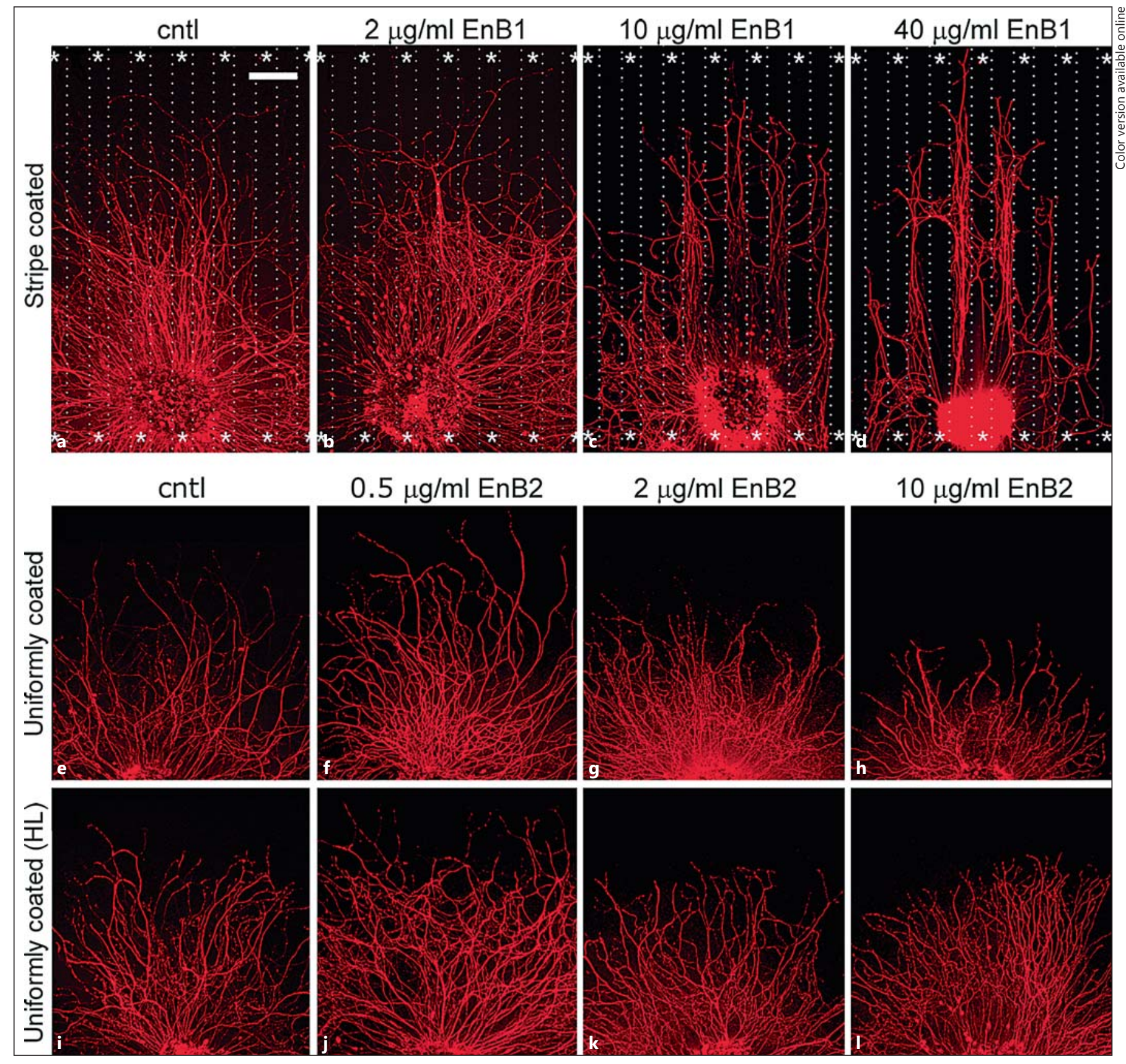

Fig. 3. Ephrin-B/EphB signaling repels and suppresses geniculate neurite outgrowth. $\mathrm{cntl}=$ Control; $\mathrm{En}=$ ephrin; $\mathrm{HL}=$ high laminin . The ephrin stripes are designated by asterisks. a-d Control stripes prepared with human IgG Fc (a) and stripes prepared with $2 \mu \mathrm{g} /$ ml ephrin-B1-Fc (b) are not repellent. Stripes prepared with $10 \mu \mathrm{g} /$ $\mathrm{ml}$ ephrin-B1-Fc (c) showed moderate repulsion, and stripes prepared with $40 \mu \mathrm{g} / \mathrm{ml}$ ephrin-B1-Fc (d) showed strong repulsion.
e-I Coverglasses that were uniformly coated with $2.5 \mu \mathrm{g} / \mathrm{ml}$ laminin and $0.5(\mathbf{f}), 2$ (g) or $10(\mathbf{h}) \mu \mathrm{g} / \mathrm{ml}$ ephrin-B2-Fc exhibited dosedependent suppression of outgrowth relative to control coverglasses (e). Suppression was not observed if a higher concentration of laminin $(20 \mu \mathrm{g} / \mathrm{ml})$ was used in combination with the same ephrin-B2-Fc concentrations (i-I). Calibration bar $=200 \mu \mathrm{m}$. 
blue bars) or NT4-stimulated (fig. 4e, purple bars) outgrowth. These data indicate that ephrin-B1 and ephrinB2 are capable of repelling and suppressing the growth of geniculate axons. We next determined whether the concentration of laminin influences the response of geniculate neurites to ephrin-B-Fc.

It has previously been reported that laminin is present in the lamina propria and core of gustatory papillae in mammals $[18,19]$, and we confirmed that laminin was concentrated in the lamina propria in the mouse (fig. $2 \mathrm{f}-$ $\left.\mathrm{g}^{\prime}\right)$ and rat (data not shown). The concentration of laminin in vivo is unknown, but it could influence the response of axons to other guidance cues. We therefore investigated whether the concentration of laminin applied to coverglasses coated with ephrin-B-Fc had an effect on repulsion or growth suppression in vitro. The experiments described above were conducted with coverglasses that were coated with a low concentration of laminin (2.5 $\mu \mathrm{g} / \mathrm{ml}$ ) following the application of ephrin-B-Fc constructs in stripes or uniform coatings. We repeated several experiments using coverglasses coated with $20 \mu \mathrm{g} / \mathrm{ml}$ ('high') laminin. High laminin significantly reduced, but did not eliminate, the repulsion of geniculate neurites by ephrin-B2-Fc stripes at E18, regardless of whether BDNF or NT4 was used to promote outgrowth (fig. 4c, compare bars with high laminin to bars with low laminin). Laminin also decreased the suppression of outgrowth by ephrin-Fc; at E15 and E18, regardless of whether BDNF or NT4 was used to promote outgrowth, no significant suppression of outgrowth was observed when high laminin was used on the coverglasses (fig. 4f, g; examples of E18 ephrin-B2 results are shown in fig. 3i-1). For one condition at E18, with coverglasses uniformly coated with 10 $\mu \mathrm{g} / \mathrm{ml}$ ephrin-B1-Fc, outgrowth was significantly stimulated compared to control coverglasses and the $0.5 \mu \mathrm{g} / \mathrm{ml}$ ephrin-B1-Fc coverglasses (fig. 4g).

\section{Ephrin-B/EphB Signaling Is Required for Proper}

Gustatory Innervation of Embryonic Fungiform Papillae

To determine whether ephrin-B/EphB signaling has an impact on gustatory innervation in vivo, we examined the innervation of fungiform papillae in the absence of EphB1 and EphB2. To assess innervation in EphB1 $1^{-/-}$ $E p h B 2^{-/-}$mice and wild-type mice, geniculate ganglion neurons in fixed mouse embryos were labeled with DiI (see Methods). In wild-type mice, extensive innervation along the length of the tongue was apparent from E13.5, prior to contact with the epithelium [44], through E17.5. At E13.5 (fig. 5a) and E15.5 (fig. 5b), we observed slightly less labeling in $E p h B 1^{-/-} / E p h B 2^{-/-}$tongues than in wild- type tongues. At E17.5, we observed a dramatic decrease in nerve labeling within fungiform papillae (fig. 5c). To quantify this difference at E17.5, we prepared vibratome sections of these specimens and control specimens and measured the thickness of the DiI-labeled chorda tympani nerve bundle at the base of the papilla epithelium, prior to arborization within the epithelium (fig. $5 c$, insets). Control nerve bundles were $9.6+1.1 \mu \mathrm{m}$ wide $(\mathrm{n}=$ 2 mice, 64 buds in total), whereas $E p h B 1^{-/-} / E p h B 2^{-/-}$ nerve bundles were $6.5+0.9 \mu \mathrm{m}$ wide $(\mathrm{n}=3$ mice, 45 buds in total), indicating a significant difference ( $p<0.05$, Student's $t$ test). Since the level of epithelial ephrin-B2 expression is low until E17.5, these data are consistent with the possibility that ephrin-B2/EphB signaling stabilizes axons during their arborization within papillae. However, because these mice had lower EphB signaling throughout development and throughout the embryo, and since innervation appeared to be decreased at earlier stages, it is also possible that earlier guidance events or neuronal survival were affected and that targeting was not specifically affected.

\section{Discussion}

Our data show that ephrin-B/EphB signaling is sufficient to repel or suppress growth from gustatory neurites in vitro and necessary for proper innervation of gustatory papillae in vivo. EphBs are expressed in the sensory afferents at targeting stages, ephrin-B1 is expressed in the pathway through which gustatory axons advance as they near fungiform papillae, and ephrin-B2 is expressed in gustatory papilla epithelium just after initial target penetration. In addition, we examined the interactions among ephrins, neurotrophins and laminin concentration in repellent signaling. To our knowledge, this is the first study to examine the role of ephrin/Eph signaling in the developing taste system.

We localized ephrin-B1, ephrin-B2, EphB1 and EphB2 in embryonic tongues at stages corresponding to target contact and target penetration. Immunolocalization of ephrin-B1 with both a monoclonal and a polyclonal antiephrin-B1 detected little ephrin-B1 in the mouse lingual epithelium from E13.5 through E17.5, prior to and following the arrival of gustatory axons at fungiform papilla epithelium (E14.5), arguing against a prominent role for ephrin-B1 in sensory axon guidance within the epithelium. Anti-ephrin-B1 did reveal a diffuse band of staining in the mesenchyme beneath the epithelium, consistent with the possibility of a guidance role prior to target con- 
tact. Ephrin-B2 and EphB localization were consistent with a role in axon termination within the lingual epithelium. In ephrin-B2 $2^{\text {lac } Z}$ mice, $\beta$-galactosidase staining was detectable as early as E15.5 in a subset of fungiform papillae, and only the most apical surface was labeled. Additional labeling was found intermittently along the nongustatory epithelium. This labeling became increasingly extensive such that by E18.5, the entire lingual epithelium was ephrin-B2 $\beta$-galactosidase positive. Ephrin-B2 immunolabeling gave similar results, although immunostaining appeared earlier than ephrin-B2 $\beta$-galactosidase detection and tended to be more continuous along the epithelium. Anti-EphB1 and anti-EphB2 weakly labeled sensory afferents. Taken together, these data are consistent with the possibility that ephrin-B2/EphB forward signaling does not occur until after afferents have pene-

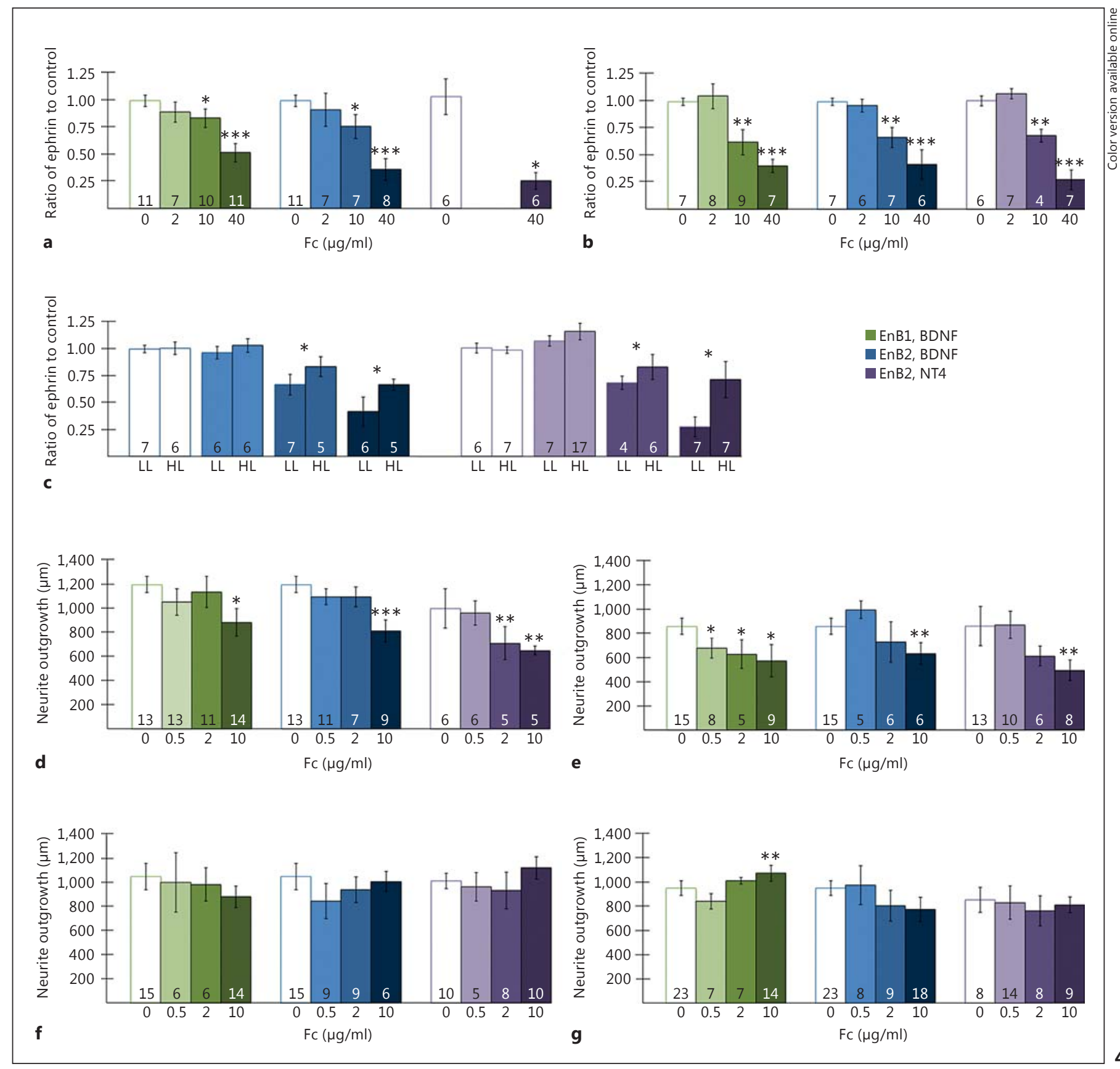

(For legend see next page.)

Ephrin-B Signaling in Gustatory Innervation
Dev Neurosci 2016;38:124-138 DOI: $10.1159 / 000444748$ 
trated the lingual epithelium. Surprisingly, we found that rat lingual sensory afferents, but not mouse lingual sensory afferents, were labeled by anti-ephrin-B2. This raises the possibility that reverse signaling occurs during sensory innervation of the rat tongue, or that cis interactions between ephrin-B2 and EphBs expressed in rat sensory axons modulate the sensitivity of these axons to trans interactions with ephrin-Bs [48].

To determine whether ephrin-B/EphB forward signaling repels geniculate neurites in vitro, we prepared coverglasses with stripes of recombinant ephrin-B-Fc fusion proteins and a uniform coating of laminin [34]. Ephrin$\mathrm{B} / \mathrm{EphB}$ forward signaling repelled E15 and E18 geniculate neurites dose dependently. Ephrin-B/EphB forward signaling can also promote the growth of neurites, typically at lower concentrations than are repellent $[49,50]$. We used coverglasses uniformly coated with a range of ephrin-B-Fc concentrations to determine whether ephrin-B-Fcs are sufficient to promote and/or suppress neurite outgrowth. In general, ephrin-B1 and ephrin-B2 did not promote geniculate neurite outgrowth at any concentration, and both tended to suppress outgrowth when $2-10 \mu \mathrm{g} / \mathrm{ml}$ of ephrin-B-Fc concentrations were used for coating.

Most experiments were conducted with BDNF in the medium to promote neurite outgrowth, because BDNF is the predominant neurotrophin expressed in fungiform papilla epithelium at targeting stages $[3,4,7,15]$. How-

Fig. 4. Ephrin-B/EphB repulsion and suppression of geniculate neurites are significant, independent of the neurotrophin used to promote growth, and reduced by high laminin. $\mathrm{HL}=$ High laminin; LL = low laminin; En = ephrin. a E15 stripe. b E18 stripe. a, b The ratio of the maximum outgrowth length in the test stripe to the maximum outgrowth length in the control stripe is plotted (see Methods). If the ratio for ephrin-B-Fc coverglasses is significantly less than for control coverglasses, we infer that the ephrin stripes are repellent. Ephrin-B1-Fc (EnB1, green bars; color in online version only) and ephrin-B2-Fc (EnB2, blue bars) stripes repel geniculate neurites dose dependently at E15 (a) and at E18 (b) when the coverglasses are coated with $2.5 \mu \mathrm{g} / \mathrm{ml}$ laminin. Similar results are obtained when NT4 is used to promote outgrowth (purple bars). Statistical significance $(p<0.05)$ was determined by ANOVA in combination with a Tukey post hoc adjustment. * Significantly different from the control stripe ratio, ${ }^{* *}$ significantly different from the control ratio and $2 \mu \mathrm{g} / \mathrm{ml}$ stripe ratio, ${ }^{* * *}$ significantly different from all other ratios in the set. c E18 stripe, high laminin vs. low laminin. Repulsion of E18 geniculate neurites by ephrin-B2-Fc stripes is significantly decreased ( $p<0.05$, Student's $\mathrm{t}$ test) when coverglasses are coated using a high laminin concentration $(20 \mu \mathrm{g} / \mathrm{ml})$ vs. low laminin $(2.5 \mu \mathrm{g} / \mathrm{ml})$, regardless of whether BDNF (blue bars) or NT4 (purple bars) is used to promote out- ever, because NT4 is over 10-fold more potent than BDNF [11], it may be present at levels that are sufficient to influence outgrowth but difficult to detect. NT4-promoted outgrowth is more sensitive than BDNF-promoted outgrowth to the repellent Sema3A [51], so it is important to determine whether it influences the response of axons to ephrin-B/EphB repulsion as well. We therefore investigated whether NT4-stimulated geniculate neurite outgrowth responded similarly to BDNF-stimulated outgrowth. We found almost no differences between NT4promoted and BDNF-promoted neurite growth on ephrin-B2-Fc-striped coverglasses or uniformly coated coverglasses.

Laminin is present within the core tissue of gustatory papilla $[16-19,52]$, so we investigated whether the level of laminin influences the response of geniculate neurites to ephrin-B-Fcs. In stripe assays, neurites were repelled less by ephrin-B-Fc stripes on high-laminin coverglasses than on low-laminin coverglasses, though repulsion occurred on both. For uniformly coated coverglasses, high laminin eliminated the suppression of outgrowth by higher concentrations of ephrin-B-Fcs. Ephrin-B expressed on cell surfaces in papilla epithelium may slow axon advance along the connective tissue core, where laminin levels may be highest, but stop axon advance among the epithelial cells, where a lower level of laminin will be encountered (fig. $2 \mathrm{f}-\mathrm{g}^{\prime}$ ).

growth. d E15 uniform. e E18 uniform. d, e On coverglasses that are uniformly coated with ephrin-B-Fcs, a low concentration of ephrin-B1-Fc (green bars) or ephrin-B2-Fc (blue or purple bars; $0.5 \mu \mathrm{g} / \mathrm{ml}$ ) did not promote geniculate neurite outgrowth, and higher concentrations $(2-10 \mu \mathrm{g} / \mathrm{ml})$ suppressed outgrowth at E15 (d) and E18 (e).f E15 uniform, high laminin. g E18 uniform, high laminin. $\mathbf{f}, \mathbf{g}$ If a high concentration of laminin $(20 \mu \mathrm{g} / \mathrm{ml})$ is used in combination with uniform coatings of ephrin-B-Fcs, suppression by ephrin-B-Fcs is blocked at E15 (f) and at E18 (g). A small increase in outgrowth was observed for the high laminin condition at E18 when $10 \mu \mathrm{g} / \mathrm{ml}$ of ephrin-B1-Fc was used to coat the coverglasses. Statistical significance $(\mathrm{p}<0.05)$ was determined by ANOVA in combination with a Tukey post hoc adjustment. * Significantly different from the control average, ${ }^{* *}$ significantly different from the control ratio and $0.5 \mu \mathrm{g} / \mathrm{ml}$ average, ${ }^{* * *}$ significantly different from all other averages in the set. In addition to the asteriskdesignated significant differences, there were two instances in which neurite outgrowth on $2 \mu \mathrm{g} / \mathrm{ml}$ ephrin-Fc-coated coverglasses was significantly different from that on $0.5 \mu \mathrm{g} / \mathrm{ml}$ ephrin-Fc coated coverglasses but not control coverglasses: e (ephrin-B2-Fc, low laminin, NT4, purple bars) and $\mathbf{g}$ (ephrin-B1-Fc, high laminin, $\mathrm{BDNF}$, green bars). The number at the base of each bar is the $n$ value for that condition. 

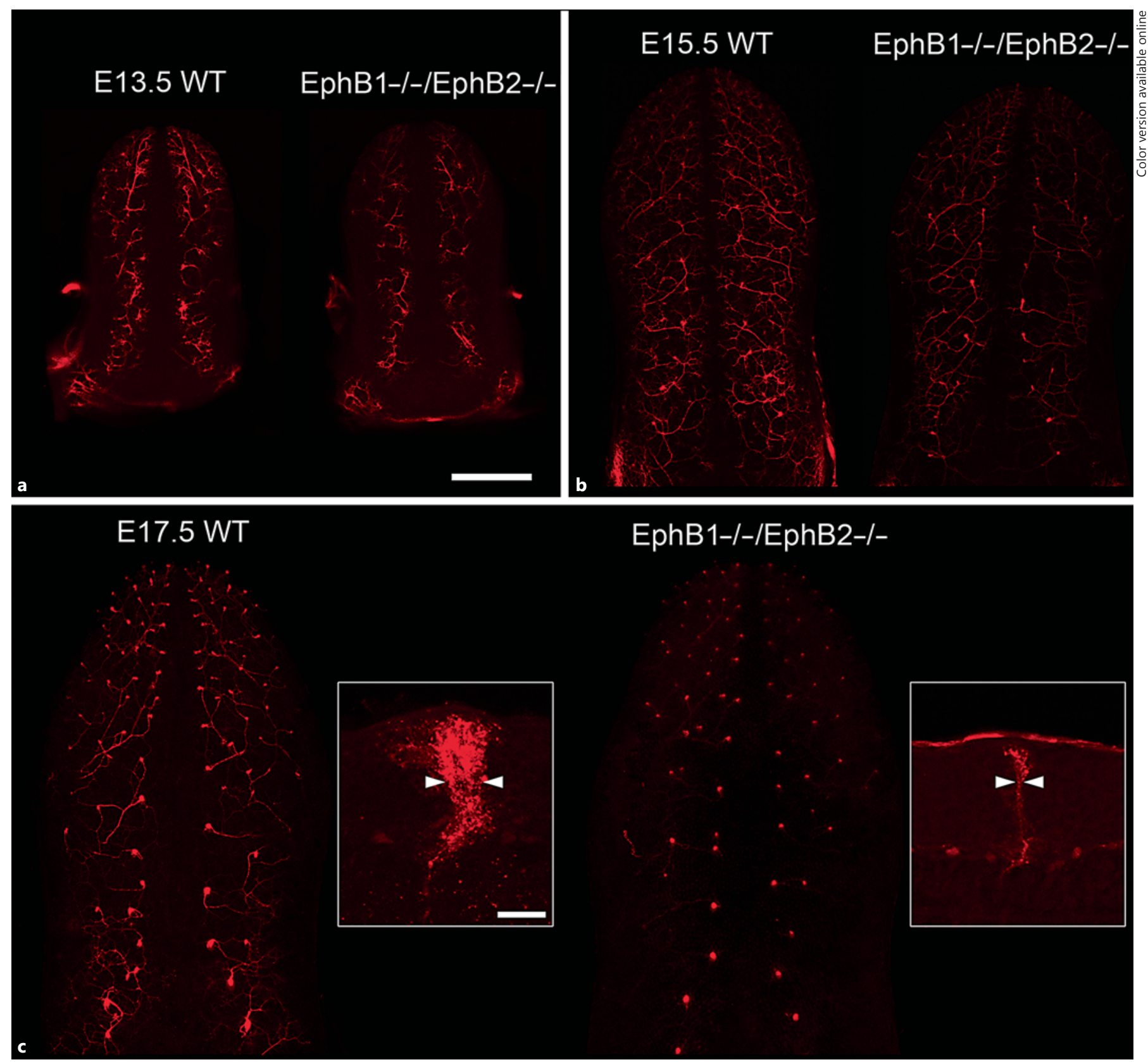

Fig. 5. Gustatory innervation of fungiform papillae is reduced in $E p h B 1^{-/-} / E p h B 2^{-/-}$mice. WT $=$Wild type. Geniculate afferents were labeled by applying DiI at the geniculate ganglion in fixed embryos (see Methods). a In E13.5 wild-type mice (a) we observed extensive nerve labeling, presumably just below the dorsal epithelium. EphB1 $1^{-/-} / E p h B 2^{--}$mice exhibited the same pattern of innervation, but labeling was somewhat less intense. b At E15.5, after the afferents have entered the fungiform papilla epithelium, $E p h B 1^{-/-} E p h B 2^{-/-}$mice again exhibit a slight decrease in the amount of innervation. c At E17.5 there was qualitatively much less innervation by geniculate axons in $E p h B 1^{-/-} / E p h B 2^{-/-}$mice than in wild-type mice. To quantify this phenomenon we prepared parasagittal vibratome sections of the E17.5 tongues and measured the width of the nerve bundle just below the point of arborization within the pretaste bud (arrowheads in insets). The average thickness of DiI-labeled geniculate nerve bundles was significantly less in mutant tongues than wild-type tongues (see Results). Calibration bar in $\mathbf{a}=500 \mu \mathrm{m}$ and applies to $\mathbf{a}-\mathbf{c}$, except the insets in $\mathbf{c}$, in which the calibration bar $=25 \mu \mathrm{m}$. 
To determine whether ephrin-B/EphB signaling is required for proper innervation of fungiform papillae in vivo, we studied innervation in $E p h B 1^{-/-} / E p h B 2^{-/-}$mice. $E p h B 1^{-/-} / E p h B 2^{-/-}$mice had slightly less chorda tympani innervation than control mice at E13.5 and E15.5, and an obvious decrease in innervation at E17.5. The slight decrease in innervation observed at E13.5 is similar to the partial loss of innervation of whisker follicles in mice lacking EphA4 [28]. The loss of whisker innervation was attributed to defasciculation of trigeminal axons prior to their arrival, which may have resulted from loss of reverse EphA4/ephrin-A signaling. In the case of gustatory afferents, loss of ephrin-B1/EphB forward signaling in the tongue mesenchyme could also have led to defasciculation prior to E13.5, as well as a partial reduction in correct targeting. We focused on the dramatic decrease in fungiform papilla innervation at E17.5, which was corroborated by a significant decrease in the thickness of the nerve bundle in the core of fungiform papillae. The correlation between loss of innervation after E15.5 and the elevation of ephrin-B2 levels in the lingual epithelium between E15.5 and E18.5 supports the possibility that maintenance of innervation depends on ephrin-B2 forward signaling through EphB1/EphB2. It is possible that geniculate axons that lack EphB1 and EphB2 are ultimately withdrawn from fungiform papilla epithelium because they are not repelled away from unsupportive areas of ephrin-B2-rich epithelium. Cochlear afferents, for example, overshoot their targets in the absence of reverse EphB/ephrin-B signaling [53] or forward ephrin-A/EphA signaling [54]. However, we did not observe overexuberant innervation of fungiform papillae epithelium in the double knockout mice. Thus, although ephrin-B2 is sufficient to repel geniculate neurites in vitro, the EphB1 $1^{-/} / E p h B 2^{-/-}$data do not provide evidence that ephrin-B2 repels or halts geniculate afferents in vivo.

Although we focused on the potential role of ephrin-B/ EphB signaling in axon targeting, we note that ephrin/ Eph interactions are also involved in epithelial cell organization $[55,56]$. In EphB3-rtTA mice, we detected lacZ activity in the mesenchyme adjacent to the epithelium at E13.5-14.5, and at E17.5 in the apical aspect of the dorsal lingual epithelium, as well as just beneath the epithelium (unpubl. data). EphB3/ephrin-B interactions were recently implicated in epithelial specialization and feather formation [57], so it will be important to determine whether EphB3 protein is present in the epithelium during fungiform papilla development. Feathers, like fungiform papillae, begin as epithelial placodes, so there may be an analogous role in fungiform papilla development. We note that EphB/ephrin-B interactions could have an indirect effect on innervation by controlling the expression of other axon guidance molecules in the epithelium and mesenchyme.

In summary, we provide the first evidence that an ephrin is expressed in lingual gustatory epithelium, that Eph$\mathrm{Bs}$ are expressed in taste axons, and that ephrin-B/EphB signaling is required for normal innervation of fungiform papillae. Our assessment of the interaction between ephrin-B forward signaling and the concentration of laminin is, we believe, the first of its kind in the study of ephrin signaling, and suggests that both the quantity and quality of competing signals influence axon targeting outcomes. Earlier studies showed that the diffusible repellent Sema3A prevents premature epithelial contact and that the diffusible attractant BDNF is necessary and sufficient for guidance into the papilla epithelium $[4,12,42,44,58]$. The current study broadens the lexicon of axon guidance mechanisms known to be involved in taste axon targeting by providing evidence for cell contact-dependent control of innervation. Our findings invite investigation of other ephrin/Eph signaling events that may influence targeting, including ephrin-A/EphA signaling. It will be important to determine whether ephrin/Eph signaling contributes to the refinement of axon terminal positions and facilitates the coordination of mutually trophic interactions between afferents and the target epithelium. Such interactions may be important not only during embryonic development but also during the reestablishment of connections that is mandated by taste cell turnover or following regeneration after injury.

\section{Acknowledgments}

The $2 \mathrm{H} 3$ antibody developed by Dodd et al. [59] and the hamster anti-ephrin-B1 and mouse anti-EphB1-3 were obtained from the Developmental Studies Hybridoma Bank developed under the auspices of the NICHD and maintained by the University of Iowa. This work was supported by an NIDCD R15 grant to M.W.R. (1R15DC010910-01) and an NIH R01 grant to M.H. (MH066332). The NIH funding agencies did not participate in the design, in the collection, analysis or interpretation of data, in the manuscript preparation or in the decision to submit the manuscript for publication. 


\section{References}

$>1$ Vilbig R, Cosmano J, Giger R, Rochlin MW: Distinct roles for Sema3A, Sema3F, and an unidentified trophic factor in controlling the advance of geniculate axons to gustatory lingual epithelium. J Neurocytol 2004;33:591606.

$>2$ Dillon TE, Saldanha J, Giger R, Verhaagen J, Rochlin MW: Sema3A regulates the timing of target contact by cranial sensory axons. J Comp Neurol 2004;470:13-24.

$>3$ Huang T, Krimm RF: BDNF and NT4 play interchangeable roles in gustatory development. Dev Biol 2014;386:308-320.

4 Huang T, Krimm RF: Developmental expression of $B d n f, N t f 4 / 5$, and TrkB in the mouse peripheral taste system. Dev Dyn 2010;239: 2637-2646.

$>5$ Lopez GF, Krimm RF: Epithelial overexpression of BDNF and NT4 produces distinct gustatory axon morphologies that disrupt initial targeting. Dev Biol 2006;292:457-468.

6 Krimm RF, Miller KK, Kitzman PH, Davis BM, Albers KM: Epithelial overexpression of BDNF or NT4 disrupts targeting of taste neurons that innervate the anterior tongue. Dev Biol 2001;232:508-521.

$>7$ Nosrat IV, Lindskog S, Seiger A, Nosrat CA: Lingual BDNF and NT-3 mRNA expression patterns and their relation to innervation in the human tongue: similarities and differences compared with rodents. J Comp Neurol 2000;417:133-152.

$>8$ Mistretta CM, Goosens KA, Farinas I, Reichardt LF: Alterations in size, number, and morphology of gustatory papillae and taste buds in BDNF null mutant mice demonstrate neural dependence of developing taste organs. J Comp Neurol 1999;409:13-24.

$\checkmark 9$ Oakley B, Brandemihl A, Cooper D, Lau D, Lawton A, Zhang C: The morphogenesis of mouse vallate gustatory epithelium and taste buds requires BDNF-dependent taste neurons. Brain Res Dev Brain Res 1998;105:8596.

$>10$ Nosrat CA, Blomlof J, ElShamy WM, Ernfors P, Olson L: Lingual deficits in BDNF and NT3 mutant mice leading to gustatory and somatosensory disturbances, respectively. Development 1997;124:1333-1342.

-11 Runge EM, Hoshino N, Biehl MJ, Ton S, Rochlin MW: Neurotrophin-4 is more potent than brain-derived neurotrophic factor in promoting, attracting and suppressing geniculate ganglion neurite outgrowth. Dev Neurosci 2012;34:389-401.

12 Hoshino N, Vatterott P, Egwiekhor A, Rochlin MW: Brain-derived neurotrophic factor attracts geniculate ganglion neurites during embryonic targeting. Dev Neurosci 2010;32: 184-196.

-13 Rosebush MS, Rao SK, Samant S, Gu W, Handorf CR, Pfeffer LM, et al: Oral cancer: enduring characteristics and emerging trends. J Mich Dent Assoc 2012;94:64-68.
14 Ringstedt T, Ibanez CF, Nosrat CA: Role of brain-derived neurotrophic factor in target invasion in the gustatory system. J Neurosci 1999; 19:3507-3518.

15 Nosrat CA, Olson L: Brain-derived neurotrophic factor mRNA is expressed in the developing taste bud-bearing tongue papillae of rat. J Comp Neurol 1995;360:698-704.

16 Triantafyllou A, Coulter P: Structural organization of subgemmal neurogenous plaques in foliate papillae of tongue. Hum Pathol 2004; 35:991-999.

17 Mbiene JP, MacCallum DK, Mistretta CM: Organ cultures of embryonic rat tongue support tongue and gustatory papilla morphogenesis in vitro without intact sensory ganglia. J Comp Neurol 1997;377:324-340.

18 Mistretta CM, Haus LF: Temporal and spatial patterns of tenascin and laminin immunore activity suggest roles for extracellular matrix in development of gustatory papillae and taste buds. J Comp Neurol 1996;364:535-555.

19 Line SR, Fortes L, Graner E, Almeida OP: Immunochemical characterization and distribution of laminin in the rat tongue. Acta Histochem 1995;97:307-312.

$20 \mathrm{Xu}$ NJ, Henkemeyer M: Ephrin reverse signaling in axon guidance and synaptogenesis. Semin Cell Dev Biol 2012;23:58-64.

21 Flanagan JG, Vanderhaeghen P: The ephrins and Eph receptors in neural development. Annu Rev Neurosci 1998;21:309-345.

22 Reber M, Hindges R, Lemke G: Eph receptors and ephrin ligands in axon guidance. Adv Exp Med Biol 2007;621:32-49.

23 Bilimoria PM, Bonni A: Molecular control of axon branching. Neuroscientist 2013;19:1624.

24 Feng G, Laskowski MB, Feldheim DA, Wang $\mathrm{H}$, Lewis R, Frisen J, et al: Roles for ephrins in positionally selective synaptogenesis between motor neurons and muscle fibers. Neuron 2000;25:295-306.

25 Donoghue MJ, Merlie JP, Sanes JR: The Eph kinase ligand $\mathrm{AL}-1$ is expressed by rostral muscles and inhibits outgrowth from caudal neurons. Mol Cell Neurosci 1996;8:185-198.

26 Munoz LM, Zayachkivsky A, Kunz RB, Hunt JM, Wang G, Scott SA: Ephrin-A5 inhibits growth of embryonic sensory neurons. Dev Biol 2005;283:397-408.

27 Moss A, Alvares D, Meredith-Middleton J, Robinson M, Slater R, Hunt SP, et al: EphrinA4 inhibits sensory neurite outgrowth and is regulated by neonatal skin wounding. Eur J Neurosci 2005;22:2413-2421.

28 North HA, Karim A, Jacquin MF, Donoghue MJ: EphA4 is necessary for spatially selective peripheral somatosensory topography. Dev Dyn 2010;239:630-638.

29 Matsunaga T, Greene MI, Davis JG: Distinct expression patterns of Eph receptors and ephrins relate to the structural organization of the adult rat peripheral vestibular system. Eur J Neurosci 2000;12:1599-1616.
30 Webber A, Raz Y: Axon guidance cues in auditory development. Anat Rec A Discov Mol Cell Evol Biol 2006;288:390-396.

-31 Kitsukawa T, Shimizu M, Sanbo M, Hirata T, Taniguchi M, Bekku Y, et al: Neuropilinsemaphorin III/D-mediated chemorepulsive signals play a crucial role in peripheral nerve projection in mice. Neuron 1997;19:9951005.

32 Cowan CA, Yokoyama N, Saxena A, Chumley MJ, Silvany RE, Baker LA, et al: Ephrin-B2 reverse signaling is required for axon pathfinding and cardiac valve formation but not early vascular development. Dev Biol 2004;271: 263-271.

33 Dravis C, Yokoyama N, Chumley MJ, Cowan CA, Silvany RE, Shay J, et al: Bidirectional signaling mediated by ephrin-B2 and EphB2 controls urorectal development. Dev Biol 2004;271:272-290.

34 Knoll B, Weinl C, Nordheim A, Bonhoeffer F: Stripe assay to examine axonal guidance and cell migration. Nat Protoc 2007;2:1216-1224.

35 Yamout A, Spec A, Cosmano J, Kashyap M, Rochlin MW: Neurotrophic factor receptor expression and in vitro nerve growth of geniculate ganglion neurons that supply divergent nerves. Dev Neurosci 2005;27:288-298.

-36 Williams SE, Mann F, Erskine L, Sakurai T, Wei S, Rossi DJ, et al: Ephrin-B2 and EphB1 mediate retinal axon divergence at the optic chiasm. Neuron 2003;39:919-935.

37 Henkemeyer M, Orioli D, Henderson JT, Saxton TM, Roder J, Pawson T, et al: Nuk controls pathfinding of commissural axons in the mammalian central nervous system. Cell 1996;86:35-46.

38 Lopez GF, Krimm RF: Refinement of innervation accuracy following initial targeting of peripheral gustatory fibers. J Neurobiol 2006;66: 1033-1043.

-39 Jevince AR, Kadison SR, Pittman AJ, Chien $\mathrm{CB}$, Kaprielian Z: Distribution of EphB receptors and ephrin-B1 in the developing vertebrate spinal cord. J Comp Neurol 2006;497: 734-750.

40 Imondi R, Wideman C, Kaprielian Z: Complementary expression of transmembrane ephrins and their receptors in the mouse spinal cord: a possible role in constraining the orientation of longitudinally projecting axons. Development 2000;127:1397-1410.

41 Ogawa Y, Takebayashi H, Takahashi M, Osumi N, Iwasaki Y, Ikenaka K: Gliogenic radial glial cells show heterogeneity in the developing mouse spinal cord. Dev Neurosci 2005;27: 364-377.

42 Krimm RF: Factors that regulate embryonic gustatory development. BMC Neurosci 2007; 8(suppl 3):S4.

43 Zhang C, Brandemihl A, Lau D, Lawton A, Oakley B: BDNF is required for the normal development of taste neurons in vivo. Neuroreport 1997;8:1013-1017. 
44 Ma L, Lopez GF, Krimm RF: Epithelial-derived brain-derived neurotrophic factor is required for gustatory neuron targeting during a critical developmental period. J Neurosci 2009;29:3354-3364.

45 Fei D, Krimm RF: Taste neurons consist of both a large TrkB-receptor-dependent and a small TrkB-receptor-independent subpopulation. PLoS One 2013;8:e83460.

46 Fritzsch B, Sarai PA, Barbacid M, Silos-Santiago I: Mice with a targeted disruption of the neurotrophin receptor trkB lose their gustatory ganglion cells early but do develop taste buds. Int J Dev Neurosci 1997;15:563-576.

47 Hansen MJ, Dallal GE, Flanagan JG: Retinal axon response to ephrin-as shows a graded, concentration-dependent transition from growth promotion to inhibition. Neuron 2004; $42: 717-730$

-48 Kao TJ, Kania A: Ephrin-mediated cis-attenuation of Eph receptor signaling is essential for spinal motor axon guidance. Neuron 2011;71:76-91.
49 Mann F, Ray S, Harris W, Holt C: Topographic mapping in dorsoventral axis of the Xenopus retinotectal system depends on signaling through ephrin-B ligands. Neuron 2002;35: 461-473.

50 McLaughlin T, O'Leary DD: Molecular gradients and development of retinotopic maps. Annu Rev Neurosci 2005;28:327-355.

51 Rochlin MW, O’Connor R, Giger RJ, Verhaagen J, Farbman AI: Comparison of neurotrophin and repellent sensitivities of early embryonic geniculate and trigeminal axons. J Comp Neurol 2000;422:579-593.

52 Jitpukdeebodintra S, Chai Y, Snead ML: Developmental patterning of the circumvallate papilla. Int J Dev Biol 2002;46:755-763.

53 Zhou CQ, Lee J, Henkemeyer MJ, Lee KH: Disruption of ephrin B/Eph B interaction results in abnormal cochlear innervation patterns. Laryngoscope 2011;121:15411547.

54 Defourny J, Poirrier AL, Lallemend F, Mateo SS, Neef J, Vanderhaeghen P, et al: EphrinA5/EphA4 signalling controls specific afferent targeting to cochlear hair cells. Nat Commun 2013;4:1438.
55 Raft S, Andrade LR, Shao D, Akiyama H, Henkemeyer M, Wu DK: Ephrin-B2 governs morphogenesis of endolymphatic sac and duct epithelia in the mouse inner ear. Dev Biol 2014;390:51-67.

56 Lin S, Wang B, Getsios S: Eph/ephrin signaling in epidermal differentiation and disease. Semin Cell Dev Biol 2012;23:92-101.

57 Suksaweang S, Jiang TX, Roybal P, Chuong CM, Widelitz R: Roles of EphB3/ephrin-B1 in feather morphogenesis. Int J Dev Biol 2012; 56:719-728.

58 Patel AV, Huang T, Krimm RF: Lingual and palatal gustatory afferents each depend on both BDNF and NT-4, but the dependence is greater for lingual than palatal afferents. J Comp Neurol 2010;518:3290-3301.

-59 Dodd J, Morton SB, Karagogeos D, Yamamoto M, Jessell TM: Spatial regulation of axonal glycoprotein expression on subsets of embryonic spinal neurons. Neuron 1988;1:105-116. 